\title{
Glycated Hemoglobin and short-term Prognosis in Patients with Acute Coronary Syndrome with Diabetes Mellitus: A Prospective Cohort Study
}

FYSAL FARUQ, SYED ALI AHSAN, MANZOOR MAHMOOD, MRM MANDAL, KAMRUZZAMAN SIDDIKI, A.B.M. GOLAM MOSTOFA, MD. AZHARUL ISLAM, AKM IMTIAZAKAND, SUJOY KUMAR SAHA, TANJIMA PARVIN

Department of Cardiology, University Cardiac Center (UCC), Bangabandhu Sheikh Mujib

Medical University, (BSMMU), Dhaka

Address of Correspondence: Dr. Fysal Faruq, Department of Cardiology, University Cardiac Center (UCC), Bangabandhu Sheikh Mujib Medical University, (BSMMU), Dhaka; E-mail:fysalfaruq@gmail.com

\begin{abstract}
:
Background: Data on the association between glycemic control after percutaneous coronary intervention (PCI) and clinical outcomes are limited and controversial in diabetic patients. Objective:The aim of the study was to assess the impact of good glycaemic control on three months clinical outcomes in diabetic acute coronary syndrome (ACS) patients undergoing PCI, from a Bangladesh health service perspective. Materials and methods: This prospective cohort study which was conducted in UCC, BSMMU included 346 consecutive diabetic ACS patients who underwent PCI at department of cardiology, BSMMU. Diabetic patients were categorized into two groups based on their 3 months HbAlc levels: 169 (48.84\%) diabetics with good glycaemic control (HbA1c < 7\%) and 177 (51.16\%) diabetics with poor glycaemic control (HbA1c $27 \%)$. The outcome was major adverse cardiovascular events (MACEs), defined as cardiac death, myocardial infarction (MI), definite stent thrombosis, target vessel revascularization and stroke. Results: At 3 months follow up, patients with poor glycaemic control had a significantly higher incidence of $M I(6.2 \%$ vs $1.2 \% ; p=0.021)$. No other adverse events were found significantly different between the groups at 3 months of PCI. Conclusion:Good glycaemic control to obtain HbAlc level $<7 \%$ in diabetic ACS patients undergoing coronary artery stenting may be beneficial in reducing the risk of MACEs and improvement of clinical outcome after PCI during 3 months follow up.
\end{abstract}

Keywords: Percutaneous coronary intervention (PCI), Acute coronary syndrome (ACS), Diabetes mellitus (DM), Major adverse cardiovascular events (MACEs).

University Heart Journal 2021; 17(2): 108-113

Introduction:

Coronary artery disease (CAD) is an increasingly important medical and public health concern, and is the leading cause of mortality in Bangladesh. Like other South Asians, Bangladeshis are unduly prone to develop CAD, which is often premature in onset, follows a rapidly progressive course and angiographically more severe. ${ }^{1}$ Diabetes is a major risk factor for CAD. It accelerates the natural course of atherosclerosis, has more tendencies for plaque rupture and involves a greater number of coronary vessels with more diffuse atherosclerotic lesions. ${ }^{2}$ Chronic hyperglycemia induces vascular endothelial injury, inflammatory reactions, reactive oxygen species, which leads to accelerated neointimal proliferation, hypofibrinolysis and prothrombotic state. ${ }^{3}$ There is consistent evidence that optimal glycaemic control (defined as $\mathrm{HbA} 1 \mathrm{c}<7 \%$ ) results in a lower incidence of microvascular complications in both type 1 and type 2 diabetes mellitus ${ }^{4}$. However, the hypothesis that optimal glycaemic control in diabetic patients would lead to asimilar improvement in clinical outcome of PCI has not been extensively investigated. HbAlc level is less influenced by acute stress. It is an indicator of average blood glucose concentrations over the preceding 2-3 months and it is also recommended as the preferred method for monitoring glycemic control in diabetic patients according to American diabetic association ${ }^{5,6,7}$ In this study, we sought to investigate a post-procedural glycaemic control in diabetic ACS patients, as reflected by plasma $\mathrm{HbA} 1 \mathrm{c}$ levels 3 months after coronary stenting, in relation to major adverse cardiovascular events (MACEs) during 3 months follow up. 


\section{Method:}

Study population: In this prospective, observational study, 365 diabetic ACS patients ( age $>18$ years and $\leq 75$ years) who underwent PCI from November 2018 to, October 2019 at UCC, BSMMU, Dhaka were consecutively enrolled after exclusion of following criteria: patients with chronic coronary syndrome, prior MI, prior revascularization, severe anaemia, pregnancy, any malignancy, chronic kidney disease, connective tissue diseases, patients receiving steroids and other drugs causing high blood glucose level and patients who received prasugrel or clopidogrel as part of dual antiplatelet therapy. The study was approved by the institutional ethical committee and all patients gave written informed consent

Methodology: The baseline characteristics, clinical presentation, detailed medical history, cardiovascular risk factors, associated comorbidities, relevant physical examination findings and investigation findings including baseline HbA1c data collected from patient's file and recorded in a semi structured data collection sheet. Coronary angiogram (CAG) and PCI were performed by respective consultant according to current practice guidelines. Two experienced cardiologists who were blinded to patient information reviewed the cine angiograms. Less than thirty percent $(<30 \%)$ residual stenosis and TIMI grade 3 flow after procedure were counted as successful PCI. Study patients received pre and post procedure medication according to guideline directed medical therapy (GDMT). During hospital stay in-hospital MACEs were observed and recorded.After index PCI patients were followed up for a period of 3 months for MACEs through outdoor basis and if necessary hospitalization. HbA1c data were collected from patients attending outdoor at 3 months following PCI. After that, study population were divided into 2 groups; good glycaemic control $(\mathrm{HbA} 1 \mathrm{c}<7 \%$ ) and poor glycaemic control (HbA1c $\leq 7 \%$ )group. Among 365 patients, 19 patients were lost to follow up. So, a total of 346 patients were available for analysis. Among them 169 patients were in good glycaemic control group and 177 patients were in poor glycaemic control group. Then their baseline characteristics, risk factors, angiographic findings and clinical outcomes were compared.

Statistical analysis: Statistical analyses were planned and reviewed by the investigators and guide. After editing, data analysis was carried out by using the Statistical Package for Social Science (SPSS) version 23.0 windows software. Numerical data were expressed as mean (SD) and analyzed by Student's t-test. Categorical data were expressed as frequency and percentages and analyzed by Chi-Square test. Binary logistic regression analyses were used to determine independent predictors of MACEs. Value of $\mathrm{p}$ less than 0.05 was considered significant

Result: The mean age of the participants of good and poor control group were $54.89 \pm 10.30$ and $55.82 \pm 10.00$ years respectively. A male predominance (84.6\% vs. $78 \%$ )was observed in either group (Figure 1). BMI of both groups were less than 23 (BMI $>23$ is considered overweight in Asian). Hypertension, dyslipidaemia, smoking and family history of coronary artery disease were found in $67.2 \%$ vs $56.8 \%, 42.4 \%$ vs $41.4 \%, 46.9 \%$ vs $49.7 \%$ and $28.8 \%$ vs $23.7 \%$ in poor and good glycaemic control group respectively (Table I). About 50.3\% of patients of good glycaemic control group and 49.2\% in poor glycaemic control group presented with STEMI (Table II). Left ventricular ejection fraction was $\leq 40 \%$ in $88.8 \%$ patients of good glycaemic control and $85.9 \%$ in the poor glycaemic control group. Average HbA1c was $6.57 \pm 0.62 \%$ in good glycaemic control group and $8.68 \pm$ $1.01 \%$ in poor glycaemic control group (Table III). Triple vessel disease was found in $22 \%$ of patients of poor glycaemic control group and $13.6 \%$ in good glycaemic control group which was statistically significant $(p=0.049)$. Single vessel disease was more common in good glycaemic control group (45.6\%) than poor glycaemic control group (31.6\%) which was statistically significant ( $\mathrm{p}=0.007$ ) (Figure 2). During 3 months follow up, patients with poor glycaemic control had a significantly higher incidence of MI (6.2\% vs $1.2 \%$; $\mathrm{p}=0.021)$. No other adverse events were found significantly different between the groups. Table VI presents binary logistic regression analysis for predictors of MACEs. After adjustment for potential confounders, the risk of MACEs in diabetic uncontrolled patients $(\mathrm{HbA} 1 \mathrm{c}>7 \%)$ was 21.14 times $(\mathrm{OR}=21.14$; 95\% CI, 4.92 90.68; $\mathrm{p}=0.0001)$. The confounders included age, sex, BMI, hypertension, dyslipidemia, smoking, renal insufficiency, family history of CAD, DVD and TVD. The findings of the study obtained from data analyses are documented below: 
Table-I

Baseline characteristics of the patients enrolled in the two groups $(N=346)$

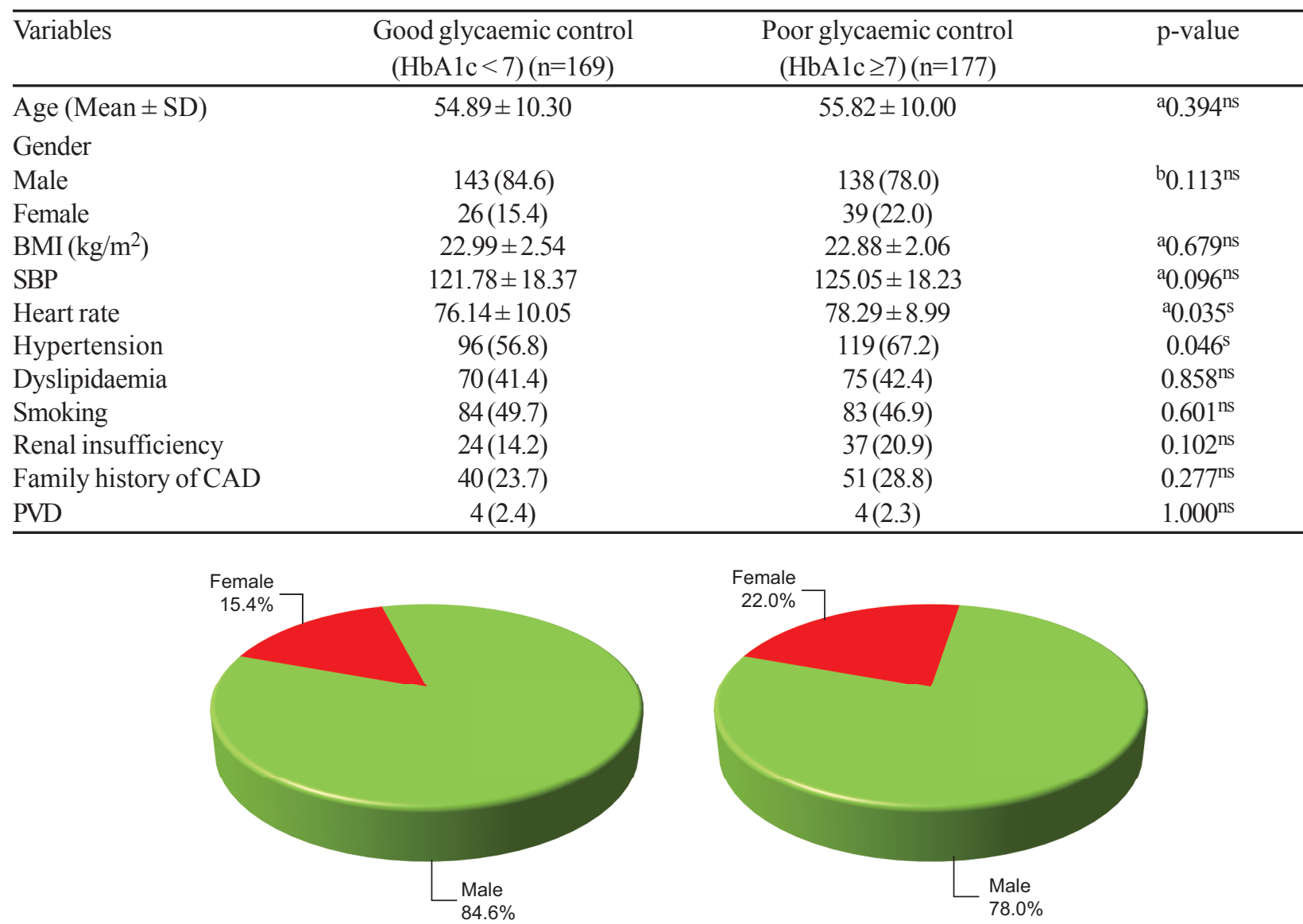

Fig.-1: Pie chart showing distribution of sex of the patients enrolled in the two groups

Table-II

Clinical presentation of the study patients $(N=346)$

\begin{tabular}{lccc}
\hline & $\begin{array}{c}\text { Good glycaemic control } \\
(\text { HbA1c }<7)(\mathrm{n}=169)\end{array}$ & $\begin{array}{c}\text { Poor glycaemic control } \\
(\text { HbA1c } \geq 7)(\mathrm{n}=177)\end{array}$ & p-value \\
\hline STEMI & $85(50.3)$ & $87(49.2)$ & $0.823^{\mathrm{ns}}$ \\
NSTEMI & $74(43.8)$ & $73(41.2)$ & $0.631^{\mathrm{ns}}$ \\
Unstable angina & $10(5.9)$ & $17(9.6)$ & $0.201^{\mathrm{ns}}$ \\
\hline
\end{tabular}

Table-III

Pre procedural investigation of the study subjects $(N=346)$

\begin{tabular}{lccc}
\hline & $\begin{array}{c}\text { Good glycaemic control } \\
(\text { HbAlc }<7)(\mathrm{n}=169)\end{array}$ & $\begin{array}{c}\text { Poor glycaemic control } \\
(\text { HbA1c } \geq 7)(\mathrm{n}=177)\end{array}$ & p-value \\
\hline Troponin I & $5.98 \pm 6.61$ & $7.66 \pm 9.91$ & ${ }^{\mathrm{a}} 0.065^{\mathrm{ns}}$ \\
S. creatinine $(\mathrm{mg} / \mathrm{dl})$ & $1.13 \pm 0.46$ & $1.18 \pm 0.43$ & ${ }^{\mathrm{a}} 0.312^{\mathrm{ns}}$ \\
$\mathrm{Hb}(\mathrm{g} / \mathrm{dl})$ & $11.61 \pm 0.96$ & $11.56 \pm 1.10$ & ${ }^{\mathrm{a}} 0.653^{\mathrm{ns}}$ \\
LVEF\% & & & $\mathrm{b}^{\mathrm{b}} 0.421^{\mathrm{ns}}$ \\
$<40$ & $19(11.2)$ & $25(14.1)$ & \\
$\geq 40$ & $150(88.8)$ & $152(85.9)$ & \\
\hline
\end{tabular}




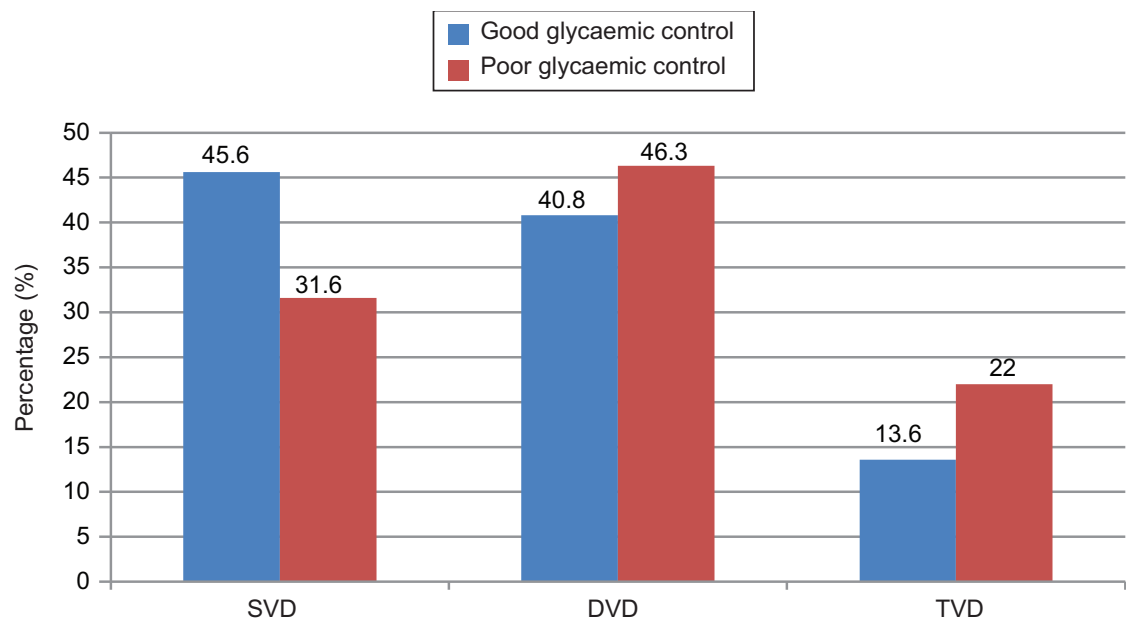

Fig.-2: Bar diagram showing the number of coronary vessel involvement of the disease of the study patients.

Table-V

Three months clinical outcomes between two groups ( $N=346)$

\begin{tabular}{lccc}
\hline $\begin{array}{l}\text { Major adverse cardiovascular } \\
\text { Events (MACEs) }\end{array}$ & $\begin{array}{c}\text { Good glycaemic control } \\
(\mathrm{HbAlc}<7)(\mathrm{n}=169)\end{array}$ & $\begin{array}{c}\text { Poor glycaemic control } \\
(\mathrm{HbAlc} \geq 7)(\mathrm{n}=177)\end{array}$ & p-value \\
\hline MI & $2(1.2)$ & $11(6.2)$ & $0.021^{\mathrm{s}}$ \\
Definite stent thrombosis & $1(0.6)$ & $2(1.1)$ & $1.000^{\text {ns }}$ \\
Target vessel revascularization & $2(1.2)$ & $5(2.8)$ & $0.449^{\text {ns }}$ \\
Stroke & $0(0.0)$ & $1(0.6)$ & $1.000^{\text {ns }}$ \\
Cardiac death & $1(0.6)$ & $3(1.7)$ & $0.623^{\text {ns }}$ \\
\hline
\end{tabular}

Table-VI

Binary logistic regression analysis for predictors of major adverse effects within 3 months $(N=346)$

\begin{tabular}{lccccccc}
\hline & \multicolumn{3}{c}{ Univariate analysis } & & \multicolumn{3}{c}{ Multivariate analysis } \\
\cline { 7 - 8 } & OR & $95 \%$ CI & p-value & & OR & $95 \%$ CI & p-value \\
\hline Age & & & 0.583 & & 1.01 & $0.97-1.04$ & $.623^{\text {ns }}$ \\
Gender (Male) & 1.04 & $0.43-2.51$ & 0.915 & & 1.10 & $0.39-3.12$ & $.851^{\text {ns }}$ \\
BMI & & & 0.947 & & 1.02 & $0.85-1.22$ & $.822^{\text {ns }}$ \\
Hypertension & 1.08 & $0.53-2.29$ & 0.819 & & 1.16 & $0.52-2.57$ & $.707^{\text {ns }}$ \\
Dyslipidaemia & 0.49 & $0.23-1.06$ & 0.069 & & 2.16 & $0.96-4.88$ & $.063^{\text {ns }}$ \\
Smoking & 0.95 & $0.47-1.90$ & 0.895 & & 1.13 & $0.49-2.61$ & $.762^{\text {ns }}$ \\
Renal insufficiency & 0.92 & $0.36-2.33$ & 0.873 & & 1.24 & $0.45-3.39$ & $.671^{\text {ns }}$ \\
Family history of CAD & 1.26 & $0.59-2.68$ & 0.540 & & 0.95 & $0.42-2.16$ & $.910^{\text {ns }}$ \\
Poor glycaemic control & 19.85 & $4.68-84.08$ & $<0.001$ & & 21.14 & $4.92-90.68$ & $.0001^{\text {s }}$ \\
DVD & 1.03 & $0.51-2.07$ & 0.918 & & 1.10 & $0.47-2.58$ & $.821^{\text {ns }}$ \\
TVD & 1.35 & $0.58-3.13$ & 0.477 & & 1.06 & $0.37-2.99$ & $.914^{\text {ns }}$ \\
\hline
\end{tabular}

\section{Discussion:}

In this single-center prospective study, we investigated the association between glycemic control status after PCI with DES and short-term clinical outcomes in patients with type 2 diabetes mellitus. Good glycemic control, as reflected by $\mathrm{HbAlc}$ measured 3 months after PCI, was associated with improved clinical outcomes: the $\mathrm{HbA} 1 \mathrm{c}<7.0$ group had a lower rate of MACEs than the HbA1c $\geq 7.0$ group 
during amedian follow-up of 3 months. This was mainly because of a decrease in MI. Hwang et al, 2017 demonstrated the 2-year incidence of MACEs was lower in the $\mathrm{HbA} 1 \mathrm{c}<7.0$ group than in the $\mathrm{HbA} 1 \mathrm{c} \geq 7.0$ group ( $27.5 \%$ versus $37.4 \%$; hazard ratio, $0.71 ; 95 \%$ confidence interval, $0.52-0.97 ; \mathrm{P}=0.03$ ), mainly because of a reduction in repeat revascularization ${ }^{8}$. In this study, triple vessel disease was found more in patients of poor glycaemic control group and single vessel disease was more common in good glycaemic control group. During 3 months follow up, patients with poor glycaemic control had a significantly higher incidence of MI ( $6.2 \%$ vs $1.2 \%, p=0.021)$. Other adverse events (cardiac death $1.7 \%$ vs $0.6 \%$; $=0.623$, stent thrombosis $1.1 \%$ vs $0.6 \%, \mathrm{p}=1.000$, TVR $2.8 \%$ vs $1.2 \%$, $\mathrm{p}=0.449$ ) were also higher in poor glycaemic control group but were not statistically significant. Several potential mechanisms might explain our findings. Hyperglycemia might have disturbed endothelial function through a reduction in the release of nitric oxide and increased superoxide production in vessel walls. Our population had higher troponin levels and a higher prevalence of STEMI, which might have affected the clinical outcomes and resultant discrepancy compared to previous studies. Clinical trials have already demonstrated that therapies that improve glycemic control decrease the risk of microvascular disease, including retinopathy, nephropathy, and neuropathy. ${ }^{9}$ However, trials attempting to decrease macrovascular events have been unsuccessful; in the Action to Control Cardiovascular Risk in Diabetes (ACCORD),${ }^{10}$ Action in Diabetes and Vascular Disease: Preterax and Diamicron Modified Release Controlled Evaluation (ADVANCE),${ }^{11}$ and Veterans Affairs Diabetes Trial (VADT) studies, ${ }^{12}$ improved glycemic control showed no reduction in the rate of cardiovascular events. In ACCORD ${ }^{11}$ trial even it was associated with increased risks of death from any cause and death from cardiovascular events. The following facts might explain the discrepant results between our study and these 3 major trials. First, we included only patients who underwent PCI, whereas the majority of patients in those trials did not. Second, patients in our study had a lower HbAlc level compared to those enrolled in the above 3 trials. Third, duration of diabetes mellitus was almost 10 years in the VADT and ACCORD trials and 8 years in the ADVANCE trial. Therefore, patients in the 3 major trials might have more advanced diabetes than our patients.In this study, it was observed that, despite receiving standard antidiabetic treatment as well as dietary advice during discharge from hospital, incidence of MACEs were higher during 3 months follow up. This might be due to so-called "metabolic memory (legacy) effect" which says memory of initial good or poor glycaemic control persists for long time and affect the clinical outcome. ${ }^{13}$

Limitation:The sample was taken from a single center. So findings may not represent the whole country. Lack of randomization might have affected the outcome of the study. Finally the current analysis presents up to 3 months outcome only. Longer-term follow up will add further insight into the problem.

\section{Conclusion:}

In conclusion, these data suggest that good glycaemic control to obtain HbA1c levels $<7 \%$ in diabetic ACS patients undergoing coronary artery stenting may be beneficial in reducing the risk of MACEs and improvement of the clinical outcome after PCI during 3 months follow-up.

\section{References:}

1. Islam AM, Majumder AA. Coronary artery disease in Bangladesh: A review. Indian heart journal. 2013 Jul $1 ; 65(4): 424-35$.

2. Wang Q, Zhang M, Torres G, Wu S, Ouyang C, Xie Z, Zou $\mathrm{MH}$. Metformin suppresses diabetes-accelerated atherosclerosis via the inhibition of Drp1-mediated mitochondrial fission. Diabetes. 2017 Jan 1;66(1):193-205.

3. McBane II RD, Hardison RM, Sobel BE, BARI 2D Study Group. Comparison of plasminogen activator inhibitor-1, tissue type plasminogen activator antigen, fibrinogen, and Ddimer levels in various age decades in patients with type 2 diabetes mellitus and stable coronary artery disease (from the BARI 2D trial). The American journal of cardiology. 2010 Jan 1; 105(1):17-24.

4. Stamler J, Vaccaro O, Neaton JD, Wentworth D: Diabetes, other risk factors, and 12-yr cardiovascular mortality for men screened in the Multiple Risk Factor Intervention Trial. Diabetes Care 1993, 16:434-44.

5. American Diabetes Association. 6. Glycemic targets: standards of medical care in diabetes-2018. Diabetes care. 2018 Jan;41(Suppl 1):S55.

6. Dunn PJ, Cole RA, Soeldner JS, Gleason RE: Reproducibility of hemoglobin AIc and sensitivity to various degrees of glucose intolerance. Ann Intern Med 1979, 91:390-96.

7. Nathan DM, Singer DE, Hurxthal K, Goodson JD: The clinical information value of the glycosylated hemoglobin assay. N Engl J Med 1984, 310:341-46.

8. Hwang JK, Lee SH, Song YB, Ahn J, Carriere K, Jang MJ, Park TK, Choi SH, Yang JH, Choi JH, Lee SH. Glycemic control status after percutaneous coronary intervention and longterm clinical outcomes in patients with type 2 diabetes mellitus. Circulation: Cardiovascular Interventions. 2017;10(4): e004157 
9. Intensive blood-glucose control with sulphonylureas or insulin compared with conventional treatment and risk of complications in patients with type 2 diabetes (UKPDS 33). UK Prospective Diabetes Study (UKPDS) Group. Lancet 1998, 352:837-53.

10. ACCORD Study Group. Effects of intensive blood-pressure control in type 2 diabetes mellitus. New England Journal of Medicine. 2010 Apr 29;362(17):1575-85.

11. ADVANCE Collaborative Group. Intensive blood glucose control and vascular outcomes in patients with type 2 diabetes. New England journal of medicine. 2008 Jun 12;358(24):2560-72.
12. Duckworth W, Abraira C, Moritz T, Reda D, Emanuele N, Reaven PD, Zieve FJ, Marks J, Davis SN, Hayward R, Warren SR. Glucose control and vascular complications in veterans with type 2 diabetes. New England journal of medicine. 2009 Jan 8;360(2):129-39.

13. Ike A, Nishikawa H, Shirai K, Mori K, Kuwano T, Fukuda Y, Takamiya Y, Yanagi D, Kubota K, Tsuchiya Y, Zhang B. Impact of glycemic control on the clinical outcome in diabetic patients with percutaneous coronary intervention. Circulation Journal. 2011:1103151150-. 